Int. J. Electrochem. Sci., 14 (2019) $4371-4382$

\title{
Synthesis and Electrochemical Performance of Polypyrrole/Graphene Nanocomposites for the Detection of Formaldehyde
}

\author{
Z. Y. Cai ${ }^{1,2, *}$, F. F. $\operatorname{Lin}^{2}$, T. Wei ${ }^{2}$, D. G. Fu ${ }^{1}$, and L. Z. Pei ${ }^{2}$ \\ ${ }^{1}$ State Key Laboratory of Bioelectronics, School of Chemistry and Chemical Engineering, Southeast \\ University, Nanjing 210096, P. R. China \\ ${ }^{2}$ Key Laboratory of Metallurgical Emission Reduction \& Resources Recycling, Ministry of Education, \\ School of Materials Science and Engineering, Anhui University of Technology, Ma'anshan, Anhui \\ 243002, P. R. China \\ *E-mail: caizhengyu0555@163.com
}

doi: $10.20964 / 2019.05 .62$

Received: 5 February 2019 / Accepted: 12 March 2019 / Published: 10 April 2019

Polypyrrole/graphene nanocomposites have been synthesized via a simple in-situ pyrrole polymerization process. The polypyrrole/graphene nanocomposites were analyzed by X-ray diffraction (XRD), scanning electron microscopy (SEM), transmission electron microscopy (TEM), highresolution TEM (HRTEM) and Fourier transform infrared spectroscopy (FTIR) spectra. The results show that the sphere-like polypyrrole particles with the size of less than $500 \mathrm{~nm}$ attach to the surface of the graphene nanosheet-shaped structures with the size of less than $10 \mu \mathrm{m}$. The polypyrrole/graphene nanocomposites modified glassy carbon electrode exhibits good electro-catalytic performance for formaldehyde in neutral solution. The nanocomposites modified glassy carbon electrode shows an irreversible current peak located at $+0.2 \mathrm{~V}$. The detection limit and linear detection range are $0.028 \mu \mathrm{M}$ and $0.001-2 \mathrm{mM}$. The polypyrrole/graphene nanocomposites reveal great potential to detect formaldehyde in liquid environment.

Keywords: Graphene/polypyrrole nanocomposites, Glassy carbon electrode, Electrochemical performance, Formaldehyde.

\section{$\underline{\text { FULL TEXT }}$}

(C) 2019 The Authors. Published by ESG (www.electrochemsci.org). This article is an open access article distributed under the terms and conditions of the Creative Commons Attribution license (http://creativecommons.org/licenses/by/4.0/). 